\title{
DELINEAMENTO AMOSTRAL EM RESERVATÓRIOS UTILIZANDO IMAGENS LANDSAT-8/OLI: UM ESTUDO DE CASO NO RESERVATÓRIO DE NOVA AVANHANDAVA (ESTADO DE SÃO PAULO, BRASIL)
}

\section{Sampling design in reservoirs based on Landsat-8/OLI images: a case study in Nova Avanhandava reservoir (São Paulo State, Brazil)}

\author{
Thanan Walesza Pequeno Rodrigues ${ }^{1}$ \\ Ulisses Silva Guimarães ${ }^{1,2}$ \\ Luiz Henrique da Silva Rotta ${ }^{1}$ \\ Fernanda Sayuri Yoshino Watanabe ${ }^{1}$ \\ Enner Alcântara ${ }^{1}$ \\ Nilton Nobuhiro Imai ${ }^{1}$ \\ ${ }^{1}$ Programa de Pós-Graduação em Ciências Cartográficas, Faculdade de Ciências e Tecnologia, \\ Departamento de Cartografia, Universidade Estadual Paulista - UNESP, \\ Rua Roberto Simonsen, 305, CEP 19060-900, Presidente Prudente, SP, Brasil \\ email: twalesza@gmail.com; luizhrotta@yahoo.com.br, fernandasyw@gmail.com, enner@fct.unesp.br, \\ nnimai@fct.unesp.br \\ 2 Sistema de Proteção da Amazônia, Centro Regional de Belém - SIPAM/CR-BE Av. Júlio César, 7060, \\ CEP 66617-420, Belém, PA, Brasil \\ email: ulisses.silva@sipam.gov.br
}

\section{Resumo:}

O uso do sensoriamento remoto voltado para a determinação de amostras de campo é de grande valia para estudos ambientais, uma vez que as imagens de satélite apresentam atributos capazes de avaliar a variabilidade espectral da superfície da água considerando uma área extensa. Desse modo, a abordagem deste trabalho objetiva definir um método de seleção estratificada de amostras baseada na variabilidade de imagens no espectro do visível e infravermelho oriundos do sensor Landsat-8/OLI. O método conta com a utilização de dados raster que representam o desvio padrão de uma série temporal de imagens Landsat-8/OLI e em seguida a definição automática de pontos de campo apoiada na técnica de amostragem estratificada aleatória. A escolha da imagem que deu origem a seleção dos pontos foi baseada na componente de maior variabilidade espectral por meio da técnica de Principal Componente. Como resultado foram obtidos vinte pontos representativos de um total de seis classes espectralmente semelhantes.

Palavras-chave: Amostragem, Sensoriamento Remoto, Geoprocessamento.

\section{Abstract:}

The use of remote sensing focused on the determination of field samples is of great value to environmental studies, since the satellite images have attributes able to assess the spectral 
variability of water surface considering a wide area. Thus, this approach aims to define a stratified working method of selecting samples based on images variability in the visible and infrared wavelengths derived from Landsat-8 / OLI sensor. The method relies on the use of raster data representing the standard deviation of a time series of images Landsat-8 / OLI and then the automatic setting field points supported by the stratified random sampling. The choice of the image that yielded the selection of the samples was based on the greatest spectral variation component by means of Principal Component technique. As a result were obtained twenty representative points of a total of six spectrally similar classes created by using a Geographic Information System.

Keywords: Sampling, Remote Sensing, Geoprocessing.

\section{Introdução}

O delineamento amostral rege os processos de seleção e inferência do valor da amostra para o valor populacional. Para que os resultados produzidos sejam expressivos e não-tendenciosos, os experimentos devem ser planejados e executados com rigor (Larson e Farber, 2010). Portanto, o pesquisador deve certificar-se de que a amostra é representativa da população. Assim, recorre-se a técnicas estatísticas que garantam inferências sobre uma população mantendo a variabilidade amostral sem viés (Lohr, 2009). Os delineamentos amostrais mais comuns são: (i) amostragem aleatória simples; (ii) amostragem estratificada; (iii) amostragem por conglomerados e (iv) amostragem sistemática.

No gerenciamento ambiental, a determinação de amostras de campo constitui etapa fundamental pois demanda tempo e recurso financeiro. Conforme Theobald et al. (2007), o design de um monitoramento requer uma análise cuidadosa dos recursos a serem monitorados, assim como, definição do que será medido, método de medição, local do monitoramento, frequência e estimação da população. No planejamento amostral é desejável que o procedimento adotado permita gerar dados com um mínimo de erro envolvido (Hedger et al., 2001).

As técnicas de amostragem são utilizadas para atender uma determinada finalidade, baseando-se em regras ou procedimentos que possam definir como uma amostra será selecionada (Frankel, 2013). É imprescindível o conhecimento do especialista na área de aplicação por entender o comportamento a priori do fenômeno e/ou evento. Em se tratando de reservatório de água existe uma expectativa para a variabilidade de parâmetros físicos associada a trechos específicos e nesse caso, a amostragem estratificada pode ser uma estratégia condizente com fins de parametrização física por permitir um desenho amostral baseado em vários subgrupos da população original, denominados estratos, cujas características são compartilhadas. A aleatoriedade se dá dentro de cada um dos estratos, permitindo assim, que cada grupo seja representado por uma ou mais amostras (Larson e Farber, 2010).

Em águas naturais, as mudanças na composição química, física e biológica são alteradas em função do período de coleta e, portanto, o regime de amostragem deve ser otimizado para atender os objetivos de um dado estudo (King et al., 2006). Pesquisando estratégias de amostragem que visam estimar a qualidade da água em lagos por meio de abordagem clássica randômica e espaço dependente, Hedger et al. (2001) observaram que para um dado tamanho de amostra, o esquema sistemático cometeu menos erros em relação ao método randômico, e para um dado erro, o esquema sistemático requereu menores amostras do que o aleatório. Os autores observaram ainda 
que o sensoriamento remoto se mostrou essencial para a obtenção de informação em ambientes dinâmicos já que fornecem dados espacialmente contíguos.

Em se tratando de dados espaciais, a coleta de dados de campo é essencial para o desenvolvimento e validação de algoritmos, assim como na sua utilização como referência para a calibração de sensores e quando sincronizados com a passagem do satélite podem ser utilizados na validação de produtos voltados para a caracterização da qualidade da água (Giardino et al. (2014). Boss e Maritorena (2006), destacam que as medidas de campo apresentam níveis de incerteza que podem estar associados a várias causas, dentre elas experimental e ambiental. A importância de se definir um desenho amostral, pode ser refletido na qualidade dos dados obtidos em campo e por conseguinte, nos produtos gerados.

Nesse sentido, o delineamento amostral em reservatórios analisados por técnicas de sensoriamento remoto e geoprocessamento são fundamentais para prover a seleção de amostras estatisticamente significativas sem viés, especialmente aplicados a áreas com dimensões entre 100 a $200 \mathrm{~km}^{2}$ atendendo coletas de campo semestrais. Por conseguinte, utiliza-se como dado primário imagens multiespectrais em séries temporais de 10 a 20 anos capazes de fornecer a variabilidade do parâmetro físico de interesse em um reservatório dinâmico submetido a alta pressão antrópica, e assim, conduz-se a melhor caracterização do meio aquático observado.

Os dados do satélite de observação terrestre Landsat são únicos no espectro eletro-óptico capazes de fornecer informação calibrada no visível e infravermelho de forma quase contínua ao longo de 43 anos o que proporciona precisão e acurácia no mapeamento de corpos d'água. A série Landsat é oriunda da colaboração entre a National Aeronautics and Space Administration (NASA) e o United States Geological Survey (USGS). Recentemente está disponível o sensor Operational Land Imager (OLI) a bordo do satélite Landsat-8 lançado em 11 de Fevereiro de 2013, operando em 9 bandas espectrais com revisita de 16 dias, permitindo utilizar informações multiespectrais ópticas com comparabilidade desde 1972 com os satélites Landsat antecessores (Roy et al., 2014).

O objetivo deste trabalho é definir um método amostral de seleção estratificada aleatória com o intuito de apoiar estudos dos parâmetros físicos em ambientes de reservatórios, baseado na variabilidade de imagens no espectro do visível e infravermelho provenientes do sistema sensor Landsat-8/OLI. Vale ressaltar que o método não prevê o estudo da qualidade da água referente ao ambiente estudado, e sim, definição de pontos amostrais com base nas características espectrais das imagens.

\section{Abordagem Estatística}

O processo que define a amostragem estratificada consiste na divisão de uma população em estratos, sendo que em cada estrato é escolhida uma amostra independente (Frankel, 2013). Em função da divisão, a heterogeneidade de cada estrato é reduzida, e portanto, torna-se mais fácil obter amostras com alta representatividade (Wang et al., 2010). Conforme Cochran (1977), estratos homogêneos podem exigir um número reduzido de observações. Esse método permite estimar e avaliar cada estrato separadamente (Rao, 2000).

A média é um parâmetro considerado intuitivamente simples e necessário nas ciências ambientais, visto que a média do estrato é diferente da população. Por exemplo, em função da variabilidade da qualidade da água em um lago, a média de um estrato tende a ser diferente quando se considera o lago inteiro. Assim, visando determinar o nível de confiança da estimativa 
da média populacional é necessário quantificar o erro padrão da estimativa (Hedger et al., 2001). Portanto, assumindo que a população apresenta $\mathrm{N}$ elementos divididos em $\mathrm{H}$ estratos, temos que a média populacional $\bar{Y}$ é dada pela Equação 1 (Frankel, 2013):

$$
\bar{Y}=\frac{1}{N} \sum_{h=1}^{H} \sum_{i=1}^{N_{h}} Y_{h i}
$$

onde $N_{h}\{h=1, \ldots, H\}$ refere-se ao número de valores da população no h (ésimo) estrato e $Y_{h i}$ representa o valor referente a variável y vinculado ao i (ésimo) elemento do h (ésimo) estrato $\left(i=1, \ldots, N_{h}\right)$.

A média para o h (ésimo) estrato é compreendida pela Equação 2:

$$
\overline{Y_{h}}=\frac{1}{N_{h}} \sum_{i=1}^{N_{h}} Y_{h i}
$$

Portanto a expressão que define a média populacional $\bar{Y}$ pode ser reescrita conforme Equação 3:

$$
\overline{Y_{h}}=\sum_{h=1}^{H} W_{h} \bar{Y}_{h}
$$

onde $W_{h}=N_{h} /_{N}$ é um estrato ponderado e reflete a proporção da população contida dentro do h (ésimo) estrato.

A média populacional global expressa como a soma ponderada de cada média do estrato fornece a chave da estimativa da população. $\bar{y}_{h}$ denota a média amostral a partir da h (ésimo) do estrato, a média populacional global $\bar{Y}$ é estimada através da Equação 4:

$$
\bar{y}_{w}=\sum_{h=1}^{H} W_{h} \bar{y}_{h}
$$

A dispersão da variância para cada estrato $S_{h}^{2}$ pode ser calculada conforme Equação 5 (Wang et al., 2012):

$$
s_{h}^{2}=\frac{1}{n_{h}-1} \sum_{i=1}^{n_{h}}\left(y_{h i}-\bar{y}_{h}\right)^{2}
$$

onde $n_{h}$ corresponde ao número de elementos do estrato.

A variância para a amostra completa é dada pela Equação 6:

$$
v\left(\bar{y}_{w}\right)=s^{2}\left(\bar{y}_{w}\right)=\frac{1}{N^{2}} \sum_{h=1}^{H} N_{h}\left(N_{h}-n_{h}\right) \frac{s_{h}^{2}}{n_{h}}
$$


O intervalo de confiança para a média da amostragem é definido como $\bar{y}_{w} \pm t s\left(\bar{y}_{w}\right)$, onde t é o teste $\mathrm{t}$.

\section{Materiais e Métodos}

\section{1 Área de Estudo}

Esta pesquisa foi desenvolvida no reservatório de Nova Avanhandava (Nav), o qual está inserido na porção oeste da Bacia Hidrográfica do Rio Tietê (Figura 1). Visando a gestão dos recursos hídricos do Estado de São Paulo, foram criadas 22 Unidades Hidrográficas de Gerenciamento de Recursos Hídricos (UGRHIs), sendo que a Bacia do Baixo Tietê recebeu a nomenclatura UGRHI 19. Essa unidade tem sua extensão a montante do rio Tietê, na barragem do reservatório de Promissão e jusante no Rio Paraná, totalizando aproximadamente $200 \mathrm{~km}$. A área de drenagem inclui os reservatórios de Nova Avanhandava e Três Irmãos (CGH-BT, 1999). O reservatório de Nav tem operação do tipo fio d'água e foi formado em 1982, inundando uma área de $210 \mathrm{~km}^{2}$ (em sua cota máxima), com extensão de 2038 m e tempo médio de residência da água em torno de 46 dias (Torloni et al., 1993). Em relação a qualidade da água, o reservatório é caracterizado como oligo-mesotrófico, com a porção superior da coluna d'água bem oxigenada, $\mathrm{pH}$ variando de levemente ácido a alcalino, condutividade relativamente elevada, e concentrações moderadas de nutrientes (Dos Santos, 2010).
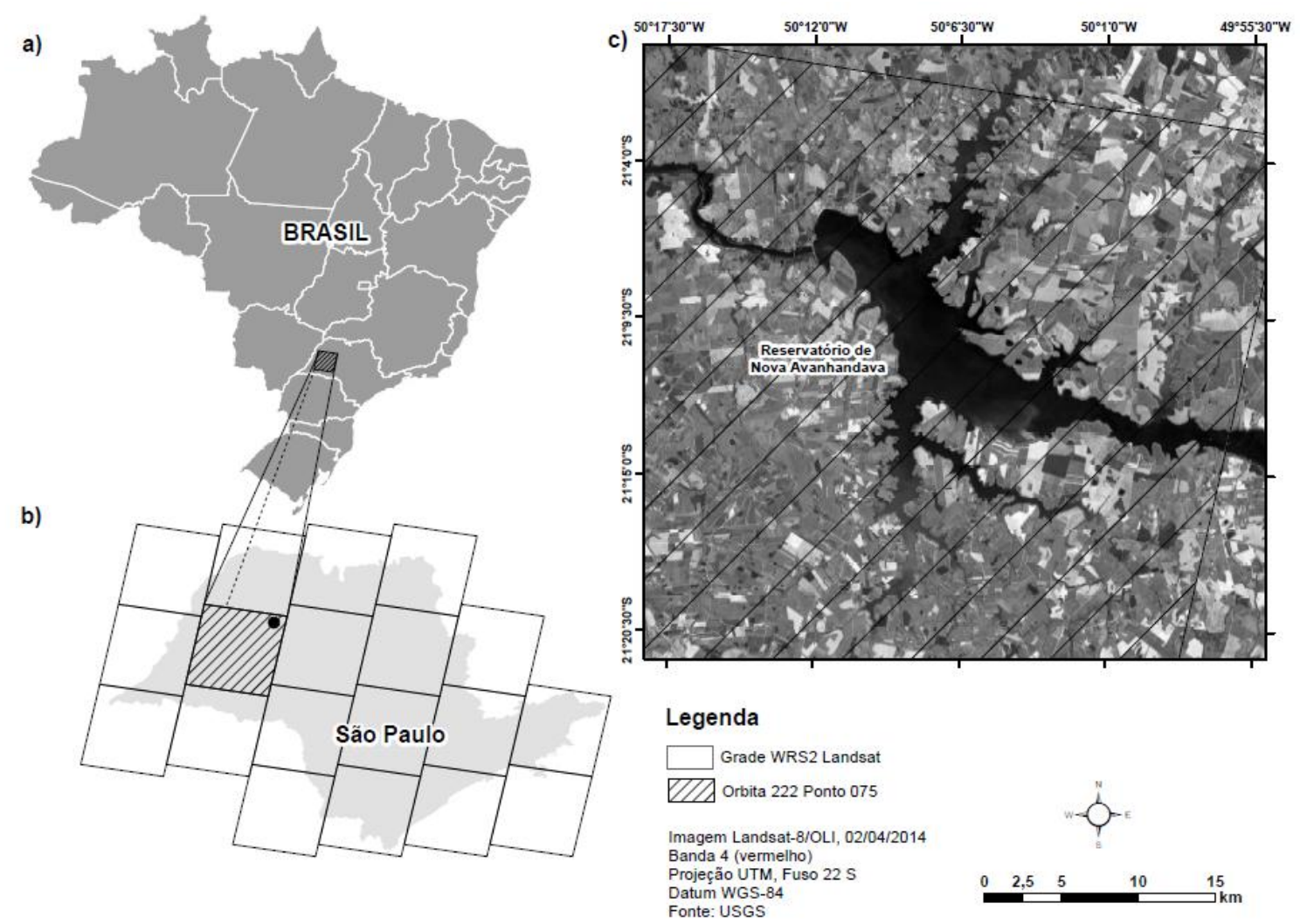

Figura 1. Área de estudo, (a) Limites estaduais; (b) Estado de São Paulo com sobreposição das cenas Landsat-8 e marcador indicando a localização do reservatório e (c) cena 222/075 Landsat8 evidenciando o reservatório de Nova Avanhandava. 


\subsection{Abordagem Metodológica}

Com base no delineamento amostral estratificado foram determinados os pontos de coleta referente a aquisicao dos dados limnológicos e ópticos no reservatório de Nav. Para tanto, foram estabelecidos procedimentos estatísticos e computacionais, com o intuito de fornecer parâmetros que subsidiassem o método de amostragem. Nesse sentido, imagens do satélite Landsat-8/OLI (Tabela 1), órbita/ ponto 222/ 075 adquiridas no site da USGS por meio do link <http://earthexplorer.usgs.gov/>, e bandas 2, 3, 4, 5, 6 e 7 foram analisadas. As novas bandas (1 e 9) foram descartadas em função da influência do espalhamento na região inferior ao azul e por retornar informação de nuvens, respectivamente.

Tabela 1. Características espectrais do sensor Operational Land Imager (OLI) do satélite Landsat 8.

\begin{tabular}{|c|c|c|}
\hline Banda & $\begin{array}{l}\text { Comprimento de Onda } \\
\text { (nm) }\end{array}$ & $\begin{array}{c}\text { Resolução } \\
\text { Espacial (m) }\end{array}$ \\
\hline Bl - Costal aerossol & $430-450$ & 30 \\
\hline B2 - Azul* & $450-510$ & 30 \\
\hline B3 - Verde* & $530-590$ & 30 \\
\hline B4 - Vermelho* & $640-670$ & 30 \\
\hline B5 - Infravermelho próximo* & $850-880$ & 30 \\
\hline B6 - SWIR 1* & $1570-1650$ & 30 \\
\hline B7 - SWIR 2* & $2110-2290$ & 30 \\
\hline B8 - Pacromática & $500-680$ & 15 \\
\hline B9 - Cirrus & $1360-1380$ & 30 \\
\hline
\end{tabular}

* Bandas utilizadas na pesquisa.

As imagens escolhidas seguiram o critério de ausência de cobertura de nuvens acima do reservatório e ausência do efeito sunglint, referente ao ciclo anual compreendido entre 2013 e 2014. O tempo de revisita do Landsat-8 é de 16 dias, portanto, em tese seria possível obter até duas imagens por mês.

As imagens hospedadas no site do USGS foram tratadas geometricamente e disponibilizadas para o usuário em nível ortorretificadas (L1T), cujos dados de referência são pontos de controle de terreno e altitudes baseadas em Modelos Digitais de Elevação (MDE), tal como SRTM (Shuttle Radar Topography Mission) (USGS, 2014). Esse tratamento permite que as imagens se sobreponham com erro geométrico menor que um pixel, e cada célula de resolução das imagens apresentem elevada correspondência com as demais referentes a outros períodos, contribuindo para a coerência geométrica na comparação das informações espectrais.

As etapas realizadas na pesquisa seguem o fluxograma abaixo (ver Figura 2). 


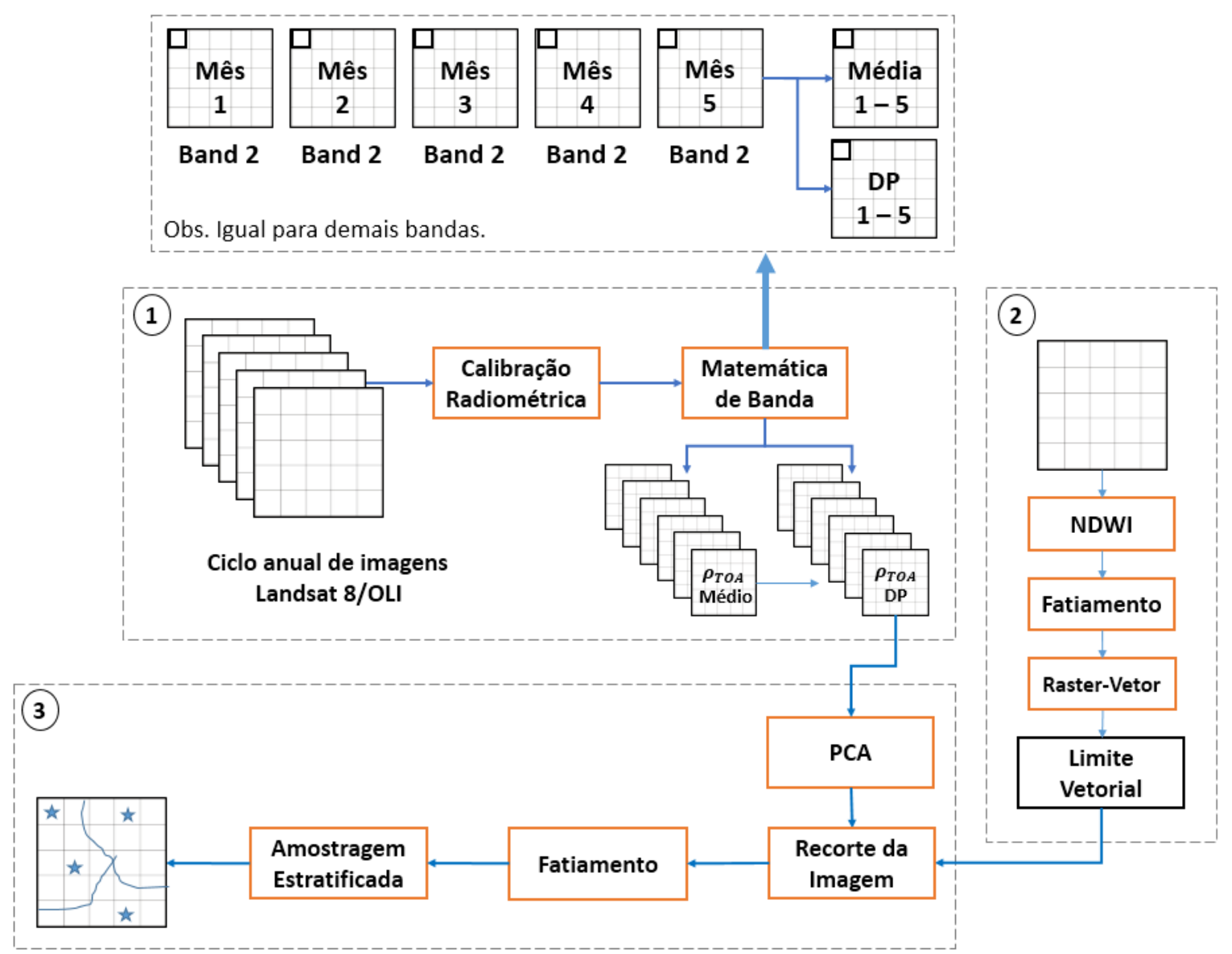

Figura 2. Esquema metodológico para definição dos pontos amostrais. $\rho_{T O A}$ representa o valor de reflectância no topo da atmosfera (TOA), DP, refere-se ao desvio padrão, NDWI (Normalized Difference Water Index) corresponde ao índice de diferença normalizada da água e PCA Análise de Principal Componente. O bloco 1, refere-se ao processamento das imagens multiespectrais; bloco 2, delimitação do reservatório e bloco 3, amostragem estratificada.

\subsubsection{Processamento das Imagens Multiespectrais}

As imagens selecionadas foram calibradas radiometricamente por meio da rotina disponível no Software ENVI 5.1. Nesse processo, os níveis digitais (ND) de cada célula da imagem são reescalonados para radiância ou reflectância no topo da atmosfera (TOA), utilizando parâmetros de ganho e offset fornecidos pelo arquivo de metadado que acompanha cada imagem (USGS, 2013a). Esse procedimento remove os efeitos causados pela diferença da geometria de iluminação (Collett et al., 1998). Trabalhos conduzidos em sistemas aquáticos mostraram que os produtos corrigidos para reflectância ou radiância no topo da atmosfera produziram resultados similares ou até melhores do que aqueles corrigidos atmosfericamente (Olmanson et al., 2011, Kutser, 2012). Estudando o material orgânico dissolvido colorido (CDOM) ao longo do tempo, por meio de imagens Landsat, Kutser (2012) observou que um modelo empírico baseado em uma razão de bandas calculado a partir de uma imagem (TOA) teve melhor desempenho do que a razão calculada com uma imagem corrigida atmosfericamente. Isso pode estar aliado ao fato de que a correção atmosférica é um processo inverso que pode introduzir alguns erros podendo interferir nas diversas bandas de diferentes maneiras (Kutser, 2012). 
Diante da dinâmica hidrológica e demais intervenções antrópicas ou naturais que o reservatório sofre ao longo do tempo é importante considerar as variações nas características químicas e biológicas do corpo d'água, com a entrada de nutrientes, oriundos de atividades agrícolas no entorno do reservatório, e ainda inserção de substâncias orgânicas e inorgânicas carreadas longitudinalmente ao longo de todo o sistema de cascata. Assim, foram consideradas duas métricas estatísticas para analisar essas variações: média e desvio padrão.

Após o processo de correção radiométrica, um conjunto de imagens referentes a um ano (2013 2014), sendo cada uma constituída por 6 bandas espectrais (bandas de 2 a 7), foram submetidas ao cálculo da média e posterior desvio padrão por meio da ferramenta Band Math disponível no ENVI 5.1. Bandas correspondentes ao mesmo comprimento de onda foram compactadas e em seguida calculados a média e o desvio padrão referentes aos meses estudados, sendo que cada pixel da imagem final apresentava o valor médio de reflectância espectral no topo da atmosfera, assim como desvio padrão.

No caso do reservatório de Nav, foi considerada uma fase alternativa em função da grande interferência do vento na superfície da água e formação de ondas. A interação da energia com a superfície irregular da água gera a chamada reflexão especular ou sunglint cuja reflexão da luz em uma dada orientação se desloca em direção ao sensor. Esse efeito é dependente da rugosidade da superfície do meio aquático, posição do sol e ângulo de visada (Kay, 2011). Assim, ao escolher as imagens para a análise deve-se fazer uma avaliação visual para identificar provável efeito de sunglint, e nesse caso, eliminar a imagem já que sua contribuição seria refletida na variabilidade espectral final.

\subsubsection{Delimitação do reservatório}

Para a delimitação do limite vetorial do reservatório de Nav foram estabelecidos alguns procedimentos, tais como a seleção da imagem referência, aplicação do índice NDWI, fatiamento, conversão raster-vetor e por fim, geração da máscara.

A escolha da imagem referência foi baseada na estação do ano, cuja taxa de precipitação é menor comparada aos outros meses. Nesse caso, dentre as imagens disponíveis, foi escolhida aquela referente ao mês de julho de 2013. Vale salientar que o reservatório por ser fio-d'água não apresenta variações abruptas em sua cota.

Com a finalidade de distinguir água dos demais alvos da imagem foi aplicado o índice NDWI proposto por McFeeters (1996) que atende a seguinte razão:

$$
N D W I=\frac{\text { Green }-N I R}{\text { Green }+N I R}
$$

onde, consideram-se as bandas do verde (Green) e do infravermelho próximo (NIR). Utilizando o Landsat-8 seriam as bandas OLI Band 3 e OLI Band 5, respectivamente.

Conforme Xu (2006), essa razão busca maximizar a reflectância da água na região do visível e minimizar o seu efeito no infravermelho. Existem modificações desse índice, como é o caso do MNDWI proposto por Xu (2006) que utiliza a razão entre as bandas do verde e do infravermelho médio (MIR) com o intuito de realçar feições com a presença de água em regiões cuja contaminação por outros alvos é evidente, como ruídos relacionados a construções, solo e vegetação provocando a superestimação das feições com água. No entanto, optou-se por manter 
a equação de McFeeters (Equation 7), uma vez que o método de amostragem prevê a aplicação de um buffer com a finalidade de evitar bordas contaminadas por outros alvos diferentes de água. A separação da água dos demais alvos foi obtida por meio do fatiamento entre valores representativos de cada alvo. Assim, pixels com valores referentes a água foram colocados em uma classe e os demais em outra classe, resultando em duas classes, água e não água. Vale salientar que a imagem escolhida para esta etapa estava isenta de nuvens sobre o reservatório, e portanto, não gerou sombras que pudessem mascarar ou interferir na delimitação do limite do corpo d'água.

A delimitação do reservatório foi realizada por meio da conversão do produto raster para o vetorial. Dessa forma, foi possível por meio da edição vetorial, separar apenas o limite do reservatório e por fim, gerar a máscara utilizada para recortar todas as imagens OLI.

\subsubsection{Amostragem estratificada por imagens multiespectrais}

Nesta etapa, as imagens desvio padrão foram utilizadas na análise de principal componente (PCA) em ambiente SIG (Sistema de Informação Geográfica) e fatiadas conforme intervalo definido empiricamente. A imagem selecionada para esta etapa foi baseada na componente de maior variabilidade do conjunto de 6 bandas desvio padrão utilizadas. $O$ fatiamento permitiu que os estratos fossem gerados para posterior definição dos pontos amostrais.

Uma etapa alternativa foi utilizada com o intuito de evitar as bordas constituídas por terra firme de modo a contaminar os resultados espectrais referentes a água. Nesse caso, criou-se um buffer interno de 70 metros do limite do corpo do reservatório visando evitar essas regiões.

Utilizando a ferramenta Hawth's Tools desenvolvida por Hawthorne Beyer (http://www.spatialecology.com/) compatível para ambiente SIG, foi possível realizar a amostragem estratificada aleatória, através da definição do número de pontos por estrato. Inicialmente foram definidos mais pontos que o requerido de forma que pudessem ser retirados manualmente pontos pouco especializados. Além disso, foi estabelecida uma distância mínima de um quilômetro entre os pontos, para evitar aglomerados. Essa etapa é semiautomática devido a intervenção final na retirada de pontos, no entanto, sem o remanejamento dos mesmos.

\subsubsection{Coleta dos dados radiométricos e limnológicos}

A campanha de campo foi realizada no reservatório de Nav entre 28 de abril a 02 de maio de 2014 e para aquisição dos dados limnológicos foram utilizados um disco de Secchi para medir a transparência da água, um turbidímetro portátil, modelo Hanna HI 93414 para medir a turbidez, e um medidor portátil, modelo Hanna HI 9146-04 para medir o oxigênio dissolvido. Amostras de água foram coletadas e armazenadas em recipientes de polietileno e refrigeradas para análise em laboratório para posterior determinação da concentração de materiais sólidos totais (MST), clorofila-a (Chl-a) e carbono orgânico dissolvido (COD). Para as análises laboratoriais foi utilizado um volume de 5 litros de água por ponto amostral. Parte dessa água foi filtrada em filtros de fibra de vidro WHATMAN GF/F com porosidade $0.7 \mu \mathrm{m}$, utilizando uma bomba de 
pressão a vácuo e os filtros foram mantidos refrigerados até análise em laboratório. Aproximadamente $300 \mathrm{ml}$ da água resultante do filtro $0.7 \mu \mathrm{m}$ foi refiltrada em filtro de membrana de nylon com porosidade de $0.2 \mu \mathrm{m}$ para a determinação da concentração de COD. A determinação da concentração de Chl-a foi obtida por extração com acetona 90\% (Golterman et al., 1978), a do MST através da metodologia descrita por APHA (1998) e do COD com base no método analítico de quantificação baseado no princípio de funcionamento do analisador TOC 5000 Shimadzu.

As curvas de $R_{s r}$ foram estimadas com base na Equação 8 de Dall'Olmo e Gitelson (2005), a partir de leituras realizadas dentro e fora da água (Mobley, 1999), utilizando medidas radiômetros hiperespectrais RAMSES TriOS®, operando na faixa espectral entre 400 a $900 \mathrm{~nm}$. Devido a resolução espectral dos radiômetros ser de $\sim 3 \mathrm{~nm}$, os dados foram submetidos a uma interpolação linear para se obter dados com variação de $1 \mathrm{~nm}$ (Imai et al., 2015). Esse procedimento visa homogeneizar as medidas entre os sensores RAMSES, uma vez que os mesmos apresentam valores de comprimento de onda diferentes. $\mathrm{O}$ método de interpolação foi também adotado por Ferreira (2014). Perfis de medidas foram tomados em cada estação amostral até uma profundidade cuja radiação representasse $1 \%$ da energia incidente no comprimento de onda do verde $(\approx 550 \mathrm{~nm})$. A geometria de aquisição segue o protocolo descrito por Mueller (2000) e Mobley (1999) e visou atender requisitos para evitar os efeitos da radiância especular e sombreamento do barco.

$$
R_{r s}=\frac{t L_{u}(\lambda)}{n^{2} E_{d}(\lambda)}
$$

onde, $L u$ é a radiância ascendente na coluna d'água; $E d$ é a irradiância descendente na coluna d'água; $t$ é a transmitância da água $(0,98)$; e $n$ é o índice de refração da água em relação ao ar $(1,33)$.

\section{Resultados e Discussão}

\subsection{Escolha das imagens}

Como apresentado na seção 3.2, a imagem escolhida para apoiar a determinação dos pontos amostrais foi baseada na ausência de nuvens e efeito de sunglint. Conforme Tabela 2, apenas cinco imagens compreendidas entre Abril de 2013 e Abril de 2014 atenderam aos critérios. 
Tabela 2. Seleção de imagens disponíveis no período compreendido entre Abril de 2013 e Abril de 2014.

\begin{tabular}{c|c|c}
\hline $\begin{array}{c}\text { Imagens } \\
\text { Disponíveis }\end{array}$ & $\begin{array}{c}\text { \%Cobertura } \\
\text { Nuvens }\end{array}$ & $\begin{array}{c}\text { Angulo azimutal } \\
\text { solar }\end{array}$ \\
\hline $\mathbf{0 1 / M a i / 2 0 1 3}$ & 0.01 & 40,14 \\
\hline $\mathbf{1 8 / J u n / 2 0 1 3}$ & 0.01 & 34.73 \\
\hline $\mathbf{0 4 / J u l / 2 0 1 3}$ & 1.26 & 35,91 \\
\hline $\mathbf{0 5 / A g o / 2 0 1 3}$ & 0,10 & 40,99 \\
\hline $\mathbf{0 2 / A b r / 2 0 1 4}$ & 0,61 & 52,41 \\
\hline
\end{tabular}

De acordo com Kay (2011), a quantidade de sunglint pode ser prevista com base na posição do sol e do sensor, assim como, utilizando técnicas estatísticas de modelagem da superfície da água. Conforme a autora, a forma mais simples de lidar com este fenômeno é escolhendo o lugar e período cuja imagem será adquirida. Na presença de sunglint, geralmente as imagens são descartadas ou então submetidas a correções. Freitas et al., (2015) apresentou resultados utilizando imagem MODIS na condição geométrica de sunglint voltado para estudos oceanográficos e constataram que o método de fusão entre produtos MODIS preservou as características radiométricas da imagem.

Para este trabalho, as imagens na condição de sunglint foram suprimidas do conjunto de dados a serem analisados por afetar consideravelmente a definição dos estratos para amostragem. A identificação do efeito de sunglint foi visual, por meio de análise da imagem na composição colorida RGB 432. Nesse caso, aplicando o teste t-student bicaudal verificou-se que as médias entre os conjuntos de dados com efeito de sunglint e sem sunglint foram estatisticamente diferentes $(p$-valor $=0,55)$, considerando um nível de significância de 5\%. Pode-se observar na Figura $3 \mathrm{~b}$, que praticamente todo o reservatório está sendo afetado pela reflexão especular, impossibilitando a visualização de diferentes massas d'água, como pode ser observado na Figura $3 \mathrm{a}$.
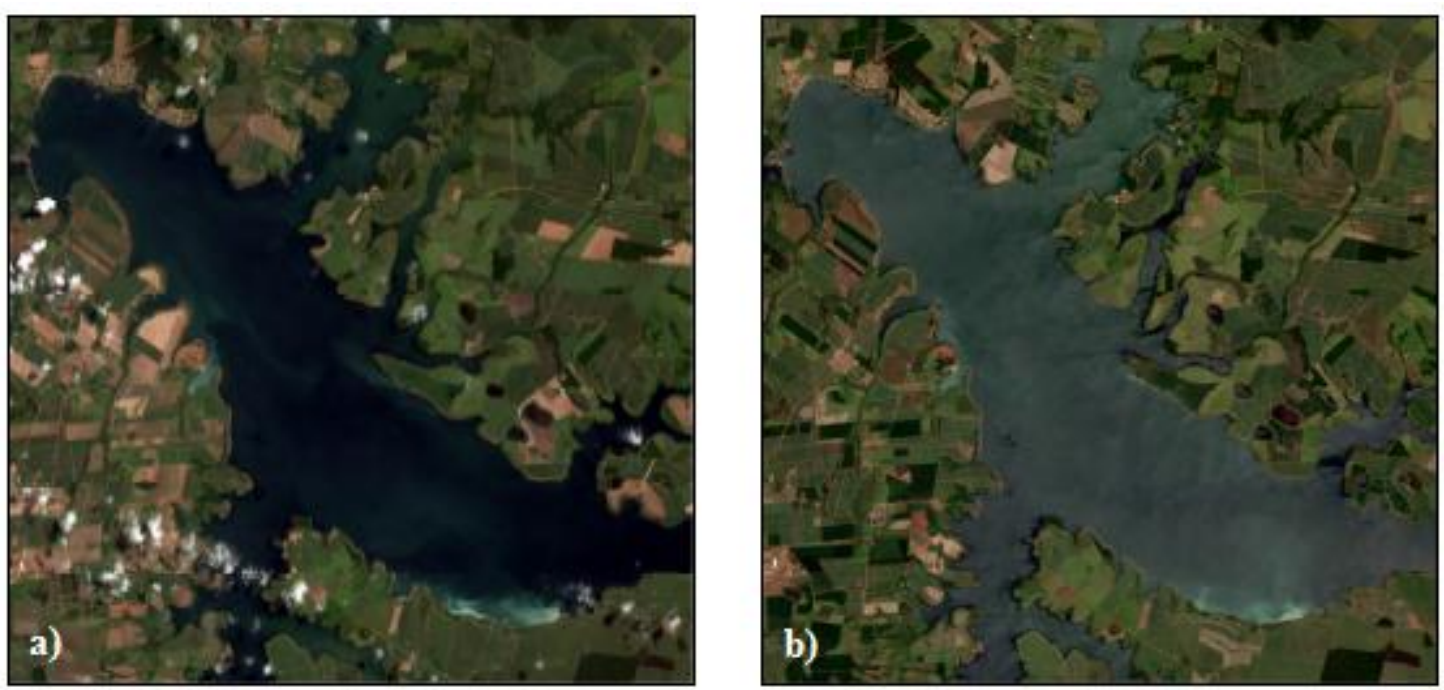

Figura 3. Imagens Landsat-8/OLI. (a) composição colorida RGB 432, 02/04/2014, vento de 1,5 $\mathrm{m} / \mathrm{s}$ (INMET) sem efeito de sunglint e (b) composição colorida RGB 432, 09/11/2013, vento de $2 \mathrm{~m} / \mathrm{s}$ (INMET) com efeito de sunglint. 


\subsection{Variabilidade espectral}

As bandas espectrais das plataformas orbitais são projetadas para atender uma determinada finalidade quanto ao monitoramento ou identificação de um alvo da superfície terrestre. No caso do Landsat-8/OLI, a banda 2 foi projetada para mapeamentos batimétricos e diferenciação entre solo e vegetação; a banda 3 realça o pico de reflexão da vegetação no visível; a banda 4 destaca a inclinação da curva espectral da vegetação, também chamada de slope; a banda 5 enfatiza o limite da vegetação entre água e solo; a banda 6 é utilizada para identificação de estresse hídrico em plantas e também é uma banda sensível a radiação emitida no termal; assim como a banda 7 , podendo detectar alvos de calor durante a noite (USGS, 2013b).

Em relação aos sistemas aquáticos, vários fatores tais como os COAs (Componentes Opticamente Ativos), afetam as propriedades ópticas e termais da água causando a modificação do sinal registrado pelos sensores ópticos situados acima da superfície da água (Giardino et al. 2014). Os sensores passivos medem energia no visível e infravermelho (400 - $1000 \mathrm{~nm})$, e são frequentemente utilizados em estudos do meio aquático. Essa faixa espectral geralmente contém a maior parte da informação referente aos constituintes da água e passíveis de detecção pelos sensores remotos (Matthews, 2011).

Conforme Ouillon et al. (2008), o aumento da concentração de (TSS) faz com que a reflectância de sensoriamento remoto $\left(R_{r s}\right)$, medida essa que relaciona a energia que sai da interface água-ar e a energia que incide no radiômetro, aumente nos comprimentos de onda entre 500 e $600 \mathrm{~nm}$. Huggins et al. (2010) observaram forte correlação da banda do vermelho dos satélites MODIS TERRA (Moderate Resolution Imaging Spectroradiometer) e Landsat-5 Thematic Mapper com a turbidez e TSS. Em relação ao CDOM, ocorre uma grande absorção de energia na região do azul, decaindo em direção aos maiores comprimentos de onda. No caso do fitoplâncton, Gitelson (1992) observou que a presença do pico em aproximadamente $680-715 \mathrm{~nm}$ está intimamente relacionada com o aumento da concentração de clorofila.

Em relação a caracterização da qualidade da água do reservatório de Nav, Galo et al. (2002) não observaram presença acentuada de espécies emersas de macrófitas ao longo das estações do ano, em contrapartida, a ocorrência de macrófitas submersas foi constatada por Cavenaghi et al. (2003) e sua presença foi atribuída a transparência da água e transmissão de luz.

Na Figura 4 é apresentada a estatística descritiva das bandas referentes aos valores de desvio padrão de $\rho_{T O A}$. Observa-se portanto, que os maiores coeficientes de variação $(\mathrm{CV}=27,65 \%$ e $26,34 \%$ ) foram encontrados nas bandas 7 e 6 , respectivamente. Vale ressaltar que as duas bandas citadas estão compreendidas no intervalo espectral do infravermelho de ondas curtas que consistem em menores reflectância e atenuação atmosférica ao se considerar alvos de reservatório de água. A banda 2 apresentou o menor CV (3,19\%) por ter maiores medias de desvio (maior reflectância) no conjunto de imagens do reservatório de água. 


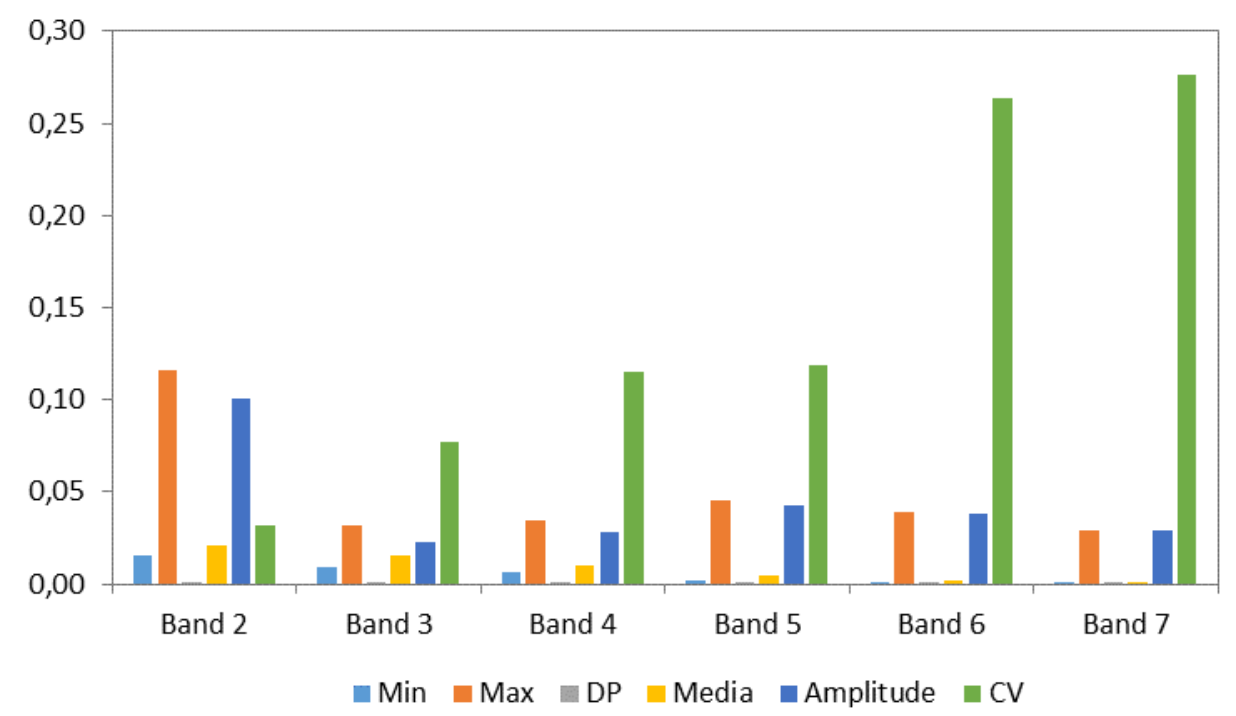

Figura 4. Estatística descritiva referente aos valores de $\rho_{T O A}$ desvio padrão.

Com base nas imagens $\rho_{T O A}$ médios, foi possível gerar as imagens $\rho_{T O A}$ desvio padrão (Figura $5)$.
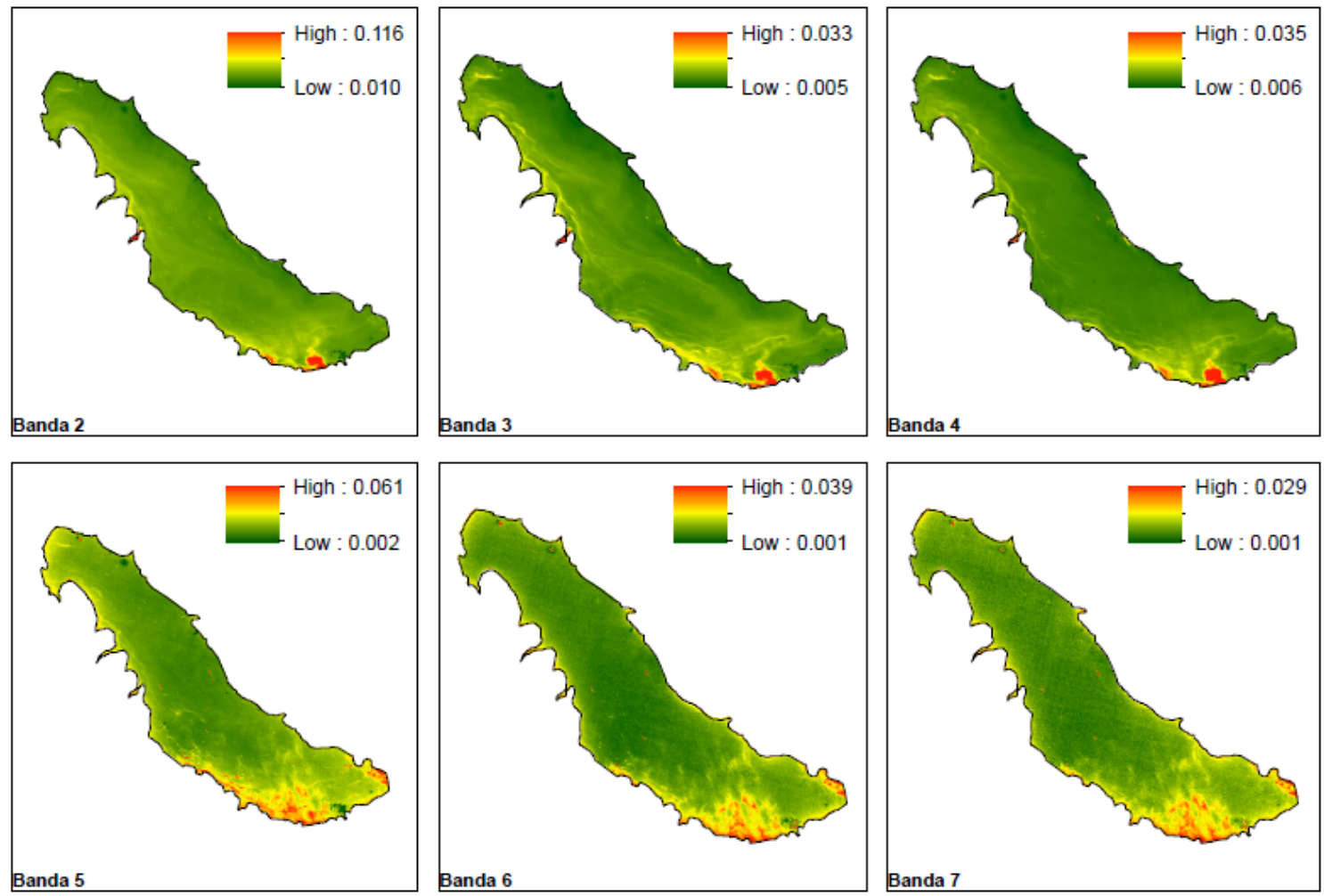

Figura 5. Imagens $\rho_{T O A}$ desvio padrão.

Observa-se na Figura 5, que existe uma região com valores de desvio padrão elevados. Essa região é comum em todas as bandas, sendo que nas bandas do infravermelho é maior do que aquelas presentes no visível. Sabe-se que em sistemas aquáticos, essas bandas são pouco utilizadas em função da alta absorção pela água, no entanto, em águas muito túrbidas a banda 
referente ao infravermelho próximo pode apresentar alta reflexão em função do material particulado em suspensão. As bandas do visível conseguem penetrar no corpo d'água e interagir com os constituintes ali presentes, e a energia retroespalhada é então captada pelo sensor (Carpenter e Carpenter, 1983).

\subsection{Fatiamento e definição dos pontos amostrais}

Visando a melhor distribuição dos pontos no reservatório optou-se por utilizar a componente de maior autovalor resultante do processo de PCA (Figura 6). Em seguida foi realizado o fatiamento e formação de seis estratos com intervalo de um desvio padrão e a imagem fatiada foi convertida para vetor com o intuito de subsidiar o processo de amostragem estratificada requerida pelo aplicativo Hawth's Tools (Figura 7).

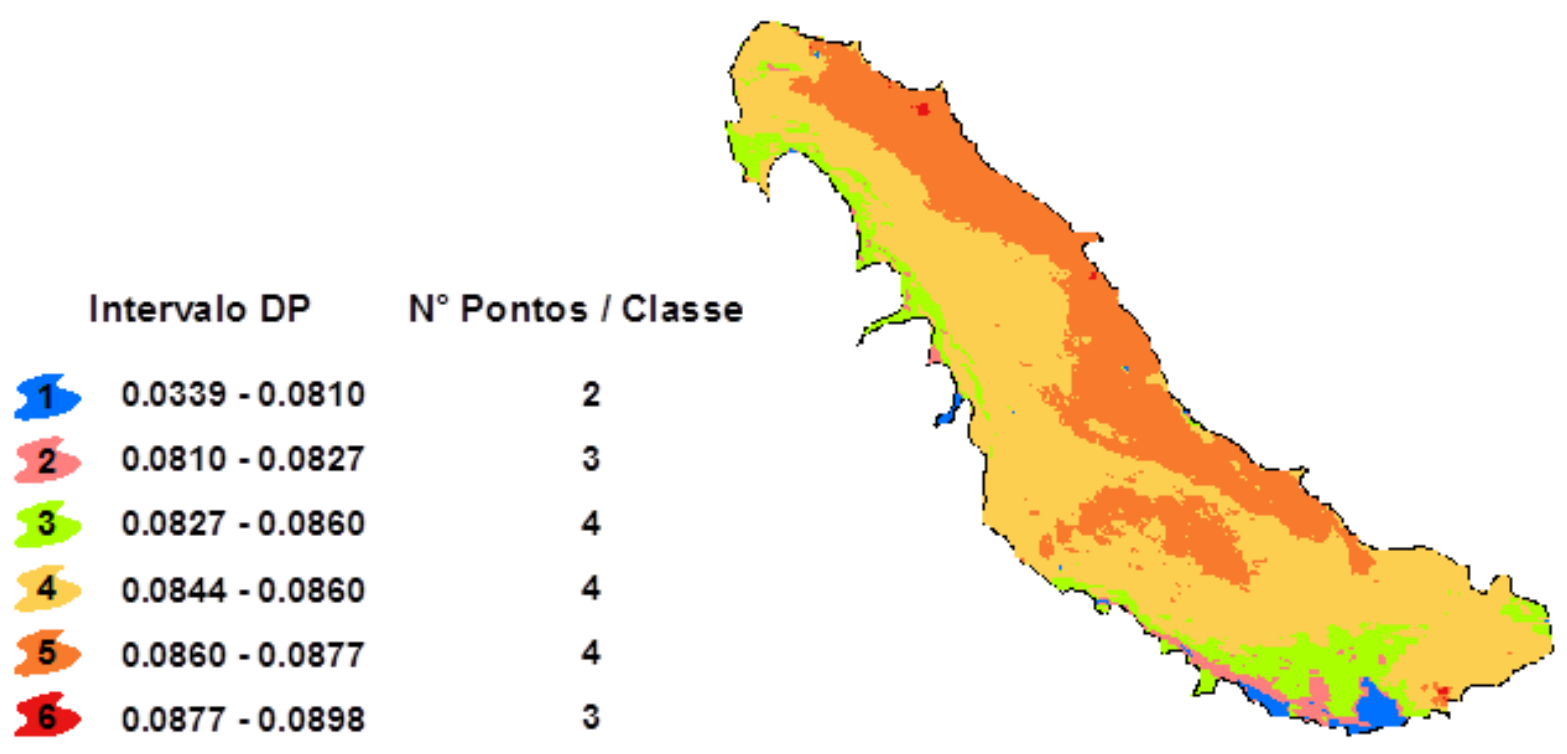

Figura 6. Imagens desvio padrão referente a banda de maior autovalor fatiada com intervalo de 1 desvio padrão.

As amostras foram criadas com base no método de amostragem estratificada, sendo que o número de amostras gerado para cada estrato seria de no mínimo 5, distantes no mínimo 1000 metros. Ao final do processo, 20 pontos foram considerados representativos da variabilidade da $\rho_{\text {TOA }}$ e contou com a eliminação dos pontos adicionais, resultando nas amostras utilizadas para apoiar as campanhas de coleta de dados limnológicos e radiométricos. O ponto 7 foi remanejado durante a campanha com a finalidade de obter informação sobre o afluente do rio Tietê. 


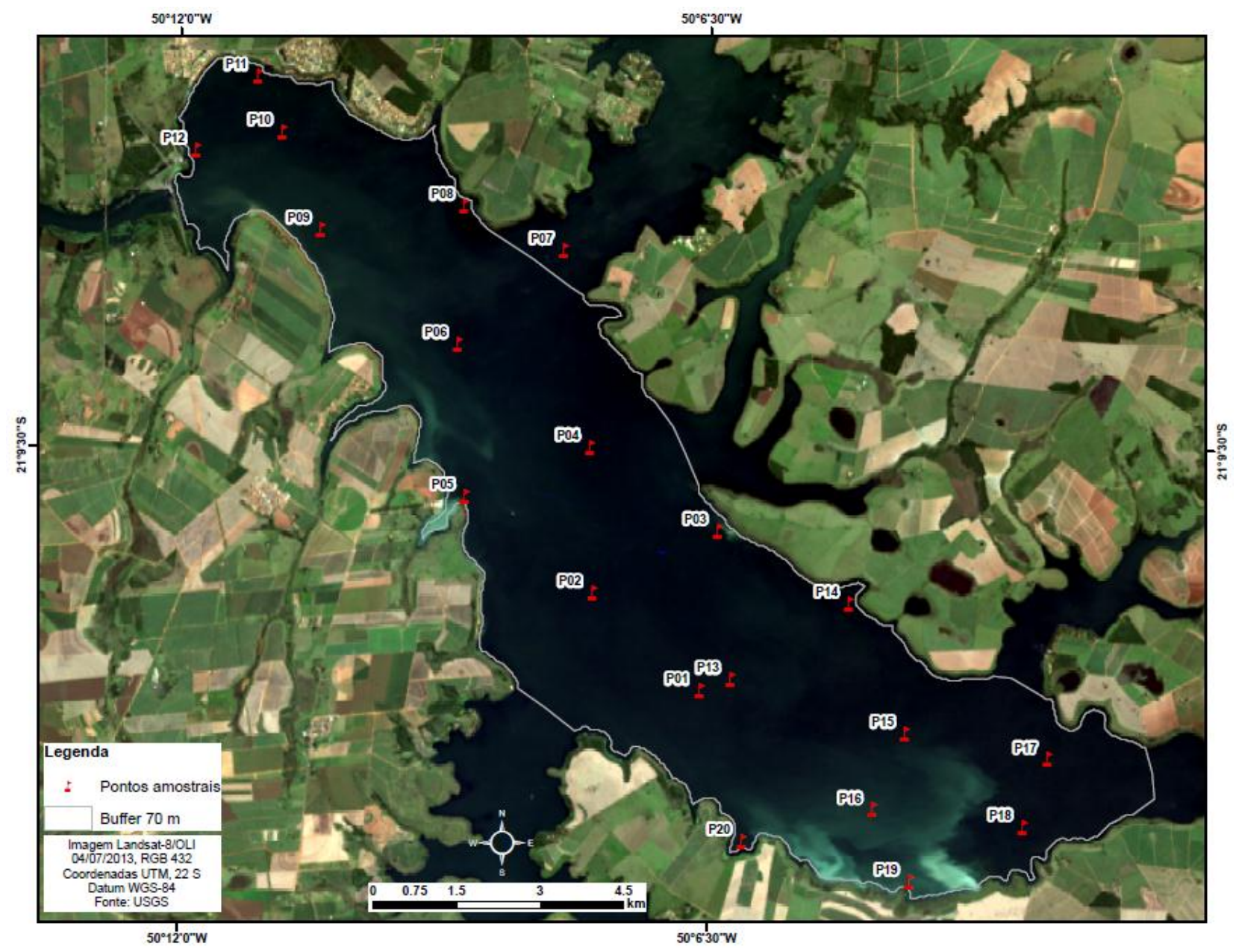

Figura 7. Mapa contendo os pontos amostrais gerados pelo método de amostragem estratificada aleatória.

\subsection{Caracterização radiométrica e limnológica de Nav}

A técnica utilizada para seleção de pontos amostrais subsidiou a coleta de amostras limnológicas e radiométricas em campo visando obter maior representatividade espectral do reservatório. Dessa forma, no que tange a caracterização limnológica, foram adquiridos os seguintes resultados (Tabela 4). 
Tabela 4. Estatística descritiva das variáveis limnológicas referentes ao campo realizado.

\begin{tabular}{|c|c|c|c|c|c|}
\hline \multirow{3}{*}{$\begin{array}{l}\text { Profundidade } \\
\text { de Sechhi (m) }\end{array}$} & Mínimo & 2,29 & \multirow{3}{*}{$\begin{array}{c}\text { MST } \\
\left(\mathrm{mg} \mathrm{l}^{-1}\right)\end{array}$} & Mínimo & 0,50 \\
\hline & Máximo & 4,20 & & Máximo & 2,60 \\
\hline & Média & $2,98 \pm 0,52$ & & Média & $1,12 \pm 0,57$ \\
\hline \multirow{3}{*}{$\begin{array}{c}\text { Turbidez } \\
\text { (NTU) }\end{array}$} & Mínimo & 1,03 & \multirow{3}{*}{$\begin{array}{l}\text { Chl-a } \\
\left(\mu \mathrm{g} . \mathrm{l}^{-1}\right)\end{array}$} & Mínimo & 2,46 \\
\hline & Máximo & 2,47 & & Máximo & 12,56 \\
\hline & Média & $1,78 \pm 0,41$ & & Média & $6,54 \pm 2,66$ \\
\hline \multirow{3}{*}{ pH } & Mínimo & 8,46 & \multirow{3}{*}{$\begin{array}{c}\text { DOC } \\
\left(\mathrm{mg} \mathrm{l}^{-1}\right)\end{array}$} & Mínimo & 11,65 \\
\hline & Máximo & 8,85 & & Máximo & 15,39 \\
\hline & Média & $8,64 \pm 0,11$ & & Média & $14,40 \pm 1,00$ \\
\hline \multirow{3}{*}{$\begin{array}{c}\text { OD } \\
\left(\mathrm{mg} \mathrm{l}^{-1}\right)\end{array}$} & Mínimo & 15,30 & \multirow{3}{*}{$\begin{array}{l}\text { Tripton } \\
\left(\mathrm{mg} \mathrm{l}^{-1}\right)\end{array}$} & Mínimo & 0,50 \\
\hline & Máximo & 20,00 & & Máximo & 2,60 \\
\hline & Média & $17,50 \pm 1,10$ & & Média & $1,12 \pm 0,57$ \\
\hline
\end{tabular}

De acordo com Dos Santos (2008), o reservatório de Nav foi classificado conforme o índice de estado trófico para a Chl- $a$, como oligotrófico em maio de 2009, mesotrófico em setembro de 2008 e eutrófico em julho de 2008 e janeiro de 2009. Em relação aos valores encontrados nesta pesquisa referente ao mês de abril de 2014 (IET $(\mathrm{Chl}-\mathrm{a})=60,11)$, o reservatório foi classificado como eutrófico.

Em geral, o reservatório de Nav é um ambiente transparente com baixa turbidez e bem oxigenado (Figura 8). Essas características podem estar associadas ao processo de filtragem gerado pela sequência de reservatórios construídos ao longo do rio Tietê (Barbosa et al., 1999, Cavenaghi et al., 2003).
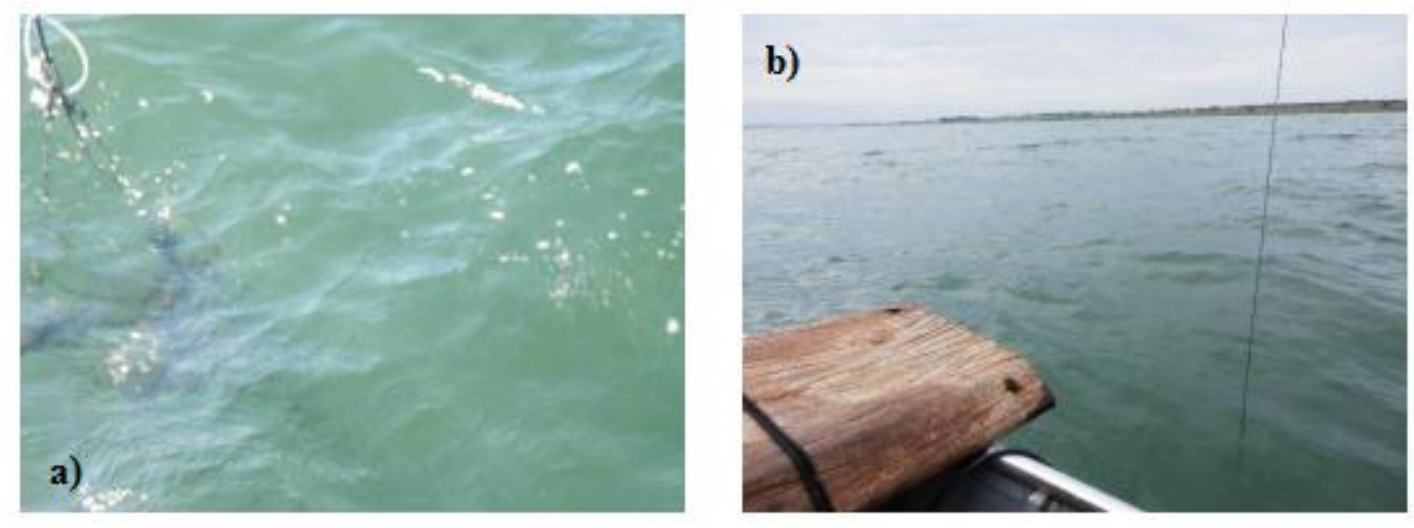

Figura 8. Visualização da cor da água em Nav no período de coleta das amostras, (a) equipamento radiométrico abaixo da superficie da água, evidenciando a transparência do ambiente, (b) Vista da margem do reservatório e novamente evidenciando a transparência da água.

Para corroborar com os dados apresentados acima, o campo contou com a aquisição de dados radiométricos com o intuito de estimar a $R_{s r}$. As curvas apresentaram as seguintes formas (Figura 9): 


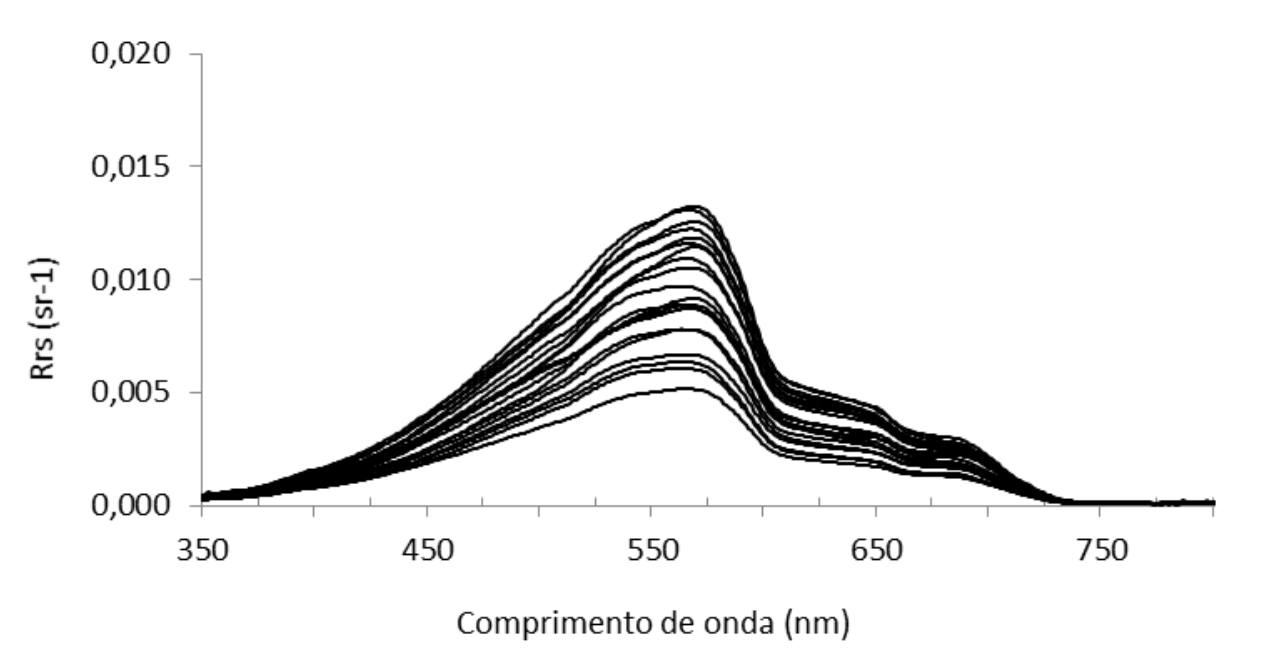

Figura 9. Curvas espectrais de $R_{s r}$ referentes ao campo realizado em abril de 2014 em Nav.

Em geral as curvas de $R_{s r}$ se referem a um ambiente com poucas feições de absorção ou picos de reflectância característicos de ambientes eutrofizados. Apesar disso a forma e magnitude das curvas são representativas de aguas túrbidas (Cheng et al., 2013). O pico próximo a $580 \mathrm{~nm}$ é função da baixa absorção de chl- $a$ e caroteno, enquanto que a feição próxima a $675 \mathrm{~nm}$ refere-se a absorção por chl- $a$. A forma pouco pronunciada na região do vermelho e infravermelho é semelhante àquela encontrada por Nascimento (2010) no reservatório de Itumbiara, Goiás e por Liew et al. (1999) na região costeira de Singapura, ambos apresentando baixa concentração de TSS $(<10 \mathrm{mg} / \mathrm{L})$ e Chl- $a(<3 \mu \mathrm{m} / \mathrm{L})$.

\section{Conclusão}

A abordagem utilizada neste trabalho foi de grande valia para definição de pontos amostrais visando aliar trabalhos limnológicos e radiométricos. Sabe-se que as características espectrais da imagem refletem o ambiente que está sendo estudado e portanto, podem ser um indicativo na geração de estratos amostrais. O método conta com algumas observações quanto ao uso das imagens, ou seja, deve-se atentar para a presença de nuvens e efeito de sunglint que alteram a resposta espectral do alvo, assim como, os valores da imagem desvio padrão. Sugere-se aplicar correção atmosférica nas imagens e verificar se haverá mudanças significativas na formação dos estratos, uma vez que a correção atmosférica ameniza o efeito da atmosfera e retorna valores físicos da superfície terrestre, como a reflectância de superfície.

O método de geração dos pontos é interativo e portanto, o usuário pode definir previamente quantos pontos utilizar e ainda, realizar testes visando obter a melhor espacialização das amostras. 


\section{AGRADECIMENTOS}

Os autores agradecem os auxílios financeiros da FAPESP (Processos N.: 2012/19821-1 e 2013/09045-7) e CNPq (Processos N.: 400881/2013-6, 472131/2012-5 e 300301/2012-0). A primeira autora agradece à CAPES pela bolsa de Doutorado.

\section{REFERÊNCIAS BIBLIOGRÁFICAS}

American Public Health Association - APHA, American Water Works Association - AWWA e Water Environment Federation - WEF. Standard methods for the examination of water and wastewater. 20th ed. (New York: APHA/AWWA/WEF, 1998), 1220.

Barbosa, F. A. R., Padisák, J., Espíndola, E. L. G., Borics, G., e Rocha, O. "The cascading reservoir continuum concept (CRCC) and its application to the river Tietê-basin, São Paulo State, Brazil". In Theoretical Reservoir Ecology and its Applications, edited by J. G. Tundisi and Milan Straškraba, 425 - 37. Michigan: Universidade de Michigan, 1999.

Boss, E., Maritorena, S. In: IOCCG Remote Sensing of Inherent Optical Properties: Fundamentals, Tests of Algorithms, and Applications, edited by Lee, Z.-P., Reports of the International Ocean-Colour Coordinating Group, No. 5, IOCCG, Dartmouth, Canada, 2006.

Carpenter, D. J., e Carpenter, S. M. "Modeling inland water quality using Landsat data". Remote Sensing of Environment, 13 (1983): 345-52.

Cavenaghi, A. L., Velini, E. D., Galo, M. L. B. T., Carvalho, F. T., Negrisoli, E.,Trindade, M. L. B. e Simionato, J. L. A. "Caracterização da qualidade de água e sedimento relacionados com a ocorrência de plantas aquáticas em cinco reservatórios da bacia do rio Tietê". Planta Daninha, 21(2003): 43-52.

Cheng, C., Wei, Y., Sun, X. e Zhou, Y. "Estimation of Chlorophyll-a Concentration in Turbid Lake Using Spectral Smoothing and Derivative Analysis". International journal of environmental research and public health, 10 (2013), 2979-94.

Cochran, W. G. Sampling Techniques, 3rd Edition. New York: John Wiley \& Sons, 1977.

Collett, L. J., Goulevitch, B. M. e Danaher, T. J. 1998. "SLATS Radiometric Correction: A Semi-automated, Multi-stage Process for the Standardisation of Temporal and Spatial Radiometric Differences, Queensland Department of Natural Resources". Paper presented ate the $9^{\text {th }}$ Australasian Remote Sensing and Photogrammetry Conference, Sydney, NSW, Australia, July 24, 1998.

Dall'olmo, G. e Gitelson, A. A. "Effect of bio-optical parameter variability on the remote estimation of chlorophyll-a concentration in turbid productive waters: experimental results". Applied Optics, 44 (2005): 412-22.

Dos Santos, R. M. "Estrutura das comunidades fitoplanctônica e zooplanctônica, com ênfase na produção secundária do zooplânctons, e fatores ambientais relacionados nos reservatórios do baixo rio Tietê, SP”. Dissertação de Mestrado, Universidade Federal de São Carlos, São Carlos, 2010. 
Ferreira, R. M. P. "Caracterização da ótica e do carbono orgânico dissolvido no reservatório de Três Marias/MG”. Dissertação de Mestrado, Instituto Nacional de Pesquisas Espaciais, São José dos Campos, 2014.

Frankel, M. "Sampling Theory". In: Handbook of survey research, edited by Rossi, P. H., Wright, J. D. e Anderson, A. B. Academic Press, 2013;

Freitas, B. F., Boggione, G. A. e Kampel, M. 2015. "Fusão de bandas MODIS na condição geométrica de sunglint para estudos oceanográficos". Paper presented at the XVII Simpósio Brasileiro de Sensoriamento Remoto - SBSR, João Pessoa-PB, Brasil, Abril 25-29, 2015.

Galo, M. L. B. T., Velini, E. D., Trindade, M. L. B. e Santos, S.C.A. "Uso do sensoriamento remoto orbital no monitoramento da dispersão de macrófitas nos reservatórios do complexo Tietê". Planta Daninha, 20 (2002): 7-20.

Giardino, C., Bresciani, M., Stroppiana, D., Oggioni, A. e Morabito, G. Optical remote sensing of lakes: an overview on Lake Maggiore. Journal of Limnology, 73 (2014): 201-214.

Gitelson, A. "The peak near $700 \mathrm{~nm}$ on radiance spectra of algae and water: relationships of its magnitude and position with chlorophyll concentration". International Journal of Remote Sensing, 13 (1992): 3367-3373.

Golterman, H. L.; Clymo, R. S. e Ohnstad, M. A. M. Methods for physical and chemical analysis of fresh water. Oxford: Blackwell Scientific, 1978.

Hedger, R. D., Atkinson, P. M. e Malthus, T. J. "Optimizing sampling strategies for estimating mean water quality in lakes using geostatistical techniques with remote sensing". Lakes \& Reservoirs: Research \& Management, 6 (2001): 279-88.

Huggins, D. G., Jakubauskas, M., Baker, D. S., e Hammer, S. 2010. "Determining the Utility and Adaptability of Remote Sensing in Monitoring and Assessing Reservoir Eutrophication and Turbidity for TMDL Assessments”. Accessed May 03, 2015.

http://kars.ku.edu/media/cpcb/datalibrary/assets/library/KBSreports/KBSrpt171_MODISfinal.pd f.

Imai, N. N., Shimabukuro, M. H., Carmo, A. F. C., Alcântara, E. H., Rodrigues, T. W. P. e Watanabe, F. S. Y. "Bo-optical data integration based on a 4D database system approach". International Archives of the Photogrammetry, Remote Sensing \& Spatial Information Sciences, 2015.

Kay, S. 2011. "Radiative transfer modelling for sun glint correction in marine satellite imagery". Doctor of Philosophy in Biological Sciences University of Exeter Accessed May 02, 2015. https://eric.exeter.ac.uk/repository/handle/10036/3523

King, L., Clarke, G., Bennion, H., Kelly, M. e Yallop, M. "Recommendations for sampling littoral diatoms in lakes for ecological status assessments". Journal of Applied Phycology, 18 (2006), 15-25.

Kutser, T. "The possibility of using the Landsat image archive for monitoring long time trends in coloured dissolved organic matter concentration in lake waters". Remote Sensing of Environment, 123 (2012): 334-38.

Larson, R. e Faber, B. Estatística Aplicada. 4. ed. São Paulo: Pearson, 2010.

Liew, S. C., Lin, I. I., Kwoh, L. K., Holmes, M., Teo, S., Gin, K. e Lim, H. 1999. "Spectral reflectance signatures of case II waters: potential for tropical algal bloom monitoring using satellite ocean color sensors". Paper presented at the 10th JSPS/VCC Joint Seminar on Marine and Fisheries Sciences, Melaka, Malasia, 1999. 
Lohr, S. Sampling: design and analysis. 2. ed. Cengage Learning, 2009.

Matthews, M. W. "A current review of empirical procedures of remote sensing in inland and near-coastal transitional waters”. International Journal of Remote Sensing, 32 (2011): 6855-99.

Mcfeeters, S. K., "The use of normalized difference water index (NDWI) in the delineation of open water features". International Journal of Remote Sensing, 17 (1996): 1425-32.

Mobley, C. D. "Estimation of the remote-sensing reflectance from above-surface measurements". Applied Optics, 38 (1999): 7442-55.

Mueller, J. L. "In-water radiometric profile measurements and data analysis protocols". In: Ocean Optics Protocols for Satellite Ocean Color Sensor Validation, Goddard Space Flight Center, edited by Fargion, G. S., Mueller, J. L. Greenbelt, Maryland, NASA Tech. Memo. 2000209966/Rev2 1, 2000. 87-97.

Nascimento, R. F. F. "Utilização de dados MERIS e in situ para a caracterização bio-óptica do reservatório de Itumbiara, GO". Dissertação de Mestrado, Instituto Nacional de Ciências Espaciais, 2010.

Olmanson, L. G., Brezonik, P. L. e Bauer, M. E. "Evaluation of medium to low resolution satellite imagery for regional lake water quality assessments". Water Resources Research, 47 (2011).

Ouillon, S., Douillet, P., Petrenko, A., Neveux, J., Dupouy, C., Froidefond, J. M., Andréfouët, S. e Muñoz-Caravaca, A. "Optical algorithms at satellite wavelengths for total suspended matter in tropical coastal waters." Sensors, 8 (2008): 4165-85.

Rao, P. S. R. S. Sampling methodologies. Chapman \& Hall/CRC, 2000.

Roy, D. P., Wulder, M. A., Loveland, T. R., Woodcock, C. E., Allen, R. G., Anderson, M. C., Helder, D., Irons, J. R., Johnson, D. M., Kennedy, R., Scambos, T. A., Schaaf, C. B., Schott, J. R., Sheng, Y., Vermote, E. F., Belward, A. S., Bindschadler, R., Cohen, W. B., Gao, F., Hipple, J. D., Hostert, P., Huntington, J., Justice, C. O., Kilic, A., Kovalskyy, V., Lee, Z. P., Lymburner, L., Masek, J. G., Mccorkel, J., Shuai, Y., Trezza, R., Vogelmann, J., Wynne, R .H. e Zhu, Z., "Landsat-8: Science and product vision for terrestrial global change research". Remote Sensing of Environment, 145 (2014): 154-72.

Theobald, D. M., Stevens Jr, D. L., White, D., Urquhart, N. S., Olsen, A. R. e Norman, J. B. "Using GIS to generate spatially balanced random survey designs for natural resource applications". Environmental Management, 40 (2007): 134-46.

Torloni, C. E., Corrêa, A., Carvalho, A., Santos, J. J., Gonçalves, J., Gereto, E., Cruz, J. A., Moreira, J. A., Silva, D. C., Deus, E. F. e Ferreira, A., 1993. "Produção pesqueira e composição das capturas em reservatórios sob concessão da CESP nos rios Tietê, Paraná e Grande no período de 1986-1991”. Serie: Produção Pesqueira, 001 - CESP, São Paulo.

United States Geological Survey. Landsat Processing Details. 2014. Accessed May 10, 2015: http://landsat.usgs.gov

United States Geological Survey. Using the USGS Landsat 8 Product. 2013a. Accessed May 10, 2015.

http://landsat.usgs.gov/Landsat8_Using_Product.php

United States Geological Survey. Landsat - A Global Land-Imaging Mission. 2013b. Acceseed May 02, 2015.

http://pubs.usgs.gov/fs/2012/3072/fs2012-3072.pdf 
Wang, J., Haining, R. e Cao, Z. "Sample surveying to estimate the mean of a heterogeneous surface: reducing the error variance through zoning". International Journal of Geographical Information Science, 24 (2010): 523-43.

Wang, J. F., Stein, A., Gao, B. B. e Ge, Y. “A review of spatial sampling”. Spatial Statistics, 2 (2012): 1-14.

$\mathrm{Xu}, \mathrm{H}$. "Modification of normalised difference water index (NDWI) to enhance open water features in remotely sensed imagery". International Journal of Remote Sensing, 27 (2006): 302533.

Recebido em junho de 2015.

Aceito em setembro de 2015. 